\title{
A composição da biografia de Severo Alexandre na História Augusta
}

Maria Luiza Corassin

Departamento de História - FFLCH/USP

A coletânea de biografias conhecidas pela denominação de História Augusta (1), abrange o período desde a ascensão de Adriano em 117 até a morte de Numeriano e Carino em 284-285. É redigida uma biografia não somente de cada um dos imperadores principais (Augusti), mas também são focalizados os co-regentes e herdeiros presuntivos (Caesares) e os usurpadores (Tyranni).

O texto foi preservado num códice do século IX, o Codex Palatinus Latinus 899, do qual derivam dezessete outras cópias, completas ou parciais, de variada precisão.

A obra é denominada no Palatinus pelo nome de Vitae Diversorum Principum et Tyrannorum a Divo Hadriano usque ad Numerianum Diversis conposit (sic), embora o título original fosse provavelmente Vita Caesarum ou Vitae Caesarum.

Desde o século XVII tornou-se conhecida como História Augusta, nome dado em 1603 pelo seu editor, o humanista protestante Isaac Casaubon, que encontrou a frase na própria obra, aplicada a Tácito, descrito como Scriptorem Historiae Augustae.

O período de Adriano a Caro, Carino e Numeriano não é abrangido integralmente. Há uma importante lacuna de 244 a 260: faltam as vidas dos imperadores que reinaram entre Gordiano III e Valeriano (Filipe, Dé-

(1) - A edição fundamental da História Augusta é a de E. HOHL, publicada na coleção Teubner (Leipzig, 1927). A obra, juntamente com a tradução para o inglês por D. MAGIE, recebeu outra edição: The Scriptores Historiae Augustae. London, W. Heinemann, 1921-1932. 3 v. 
cio, Treboniano, Volusiano), assim como a maior parte da biografia do próprio Valeriano, da qual foi conservada somente a parte final.

A H.A. segue a tradição biográfica já existente em Stuetônio e Mário Máximo. Desprezando o estilo retórico, prefere um latim despretencioso, compondo vidas romanceadas para leitura das camadas senatoriais. Este tipo de leitura agradava os senadores, como Amiano Marcelino observava com despeito. Há ampla concessão ao gosto dos leitores pela bisbilhotice e detalhes mínimos sobre os imperadores.

A tradição manuscrita coloca ostensivamente cada biografia sob a autoria de um escritor, como é indicado no próprio título da coletânea. Conhecemos assim o nome de seis autores: Élio Espartiano, Júlio Capitolino, Vulcácio Galicano, Élio Lamprídio, Trebélio Pólio e Flávio Vopisco. Estes escritores não são registrados por nehuma outra fonte; contudo, se déssemos crédito a certas passagens da H.A., eles aparentemente se conheciam entre si.

Pólio e Vopisco são os responsáveis pelas vidas de Valeriano até Numeriano. As vidas iniciais, de Adriano a Gordiano III, são divididas entre os outros quatro; a Galicano é atribuída somente uma, a do usurpador Avídio Cássio. Espartiano, Capitolino e Lamprídio virtualmente cobrem, portanto, o período de 117 a 244. São creditadas a Lamprídio as vidas de Cômodo, Diadúmeno, Heliogábalo e Severo Alexandre.

Algumas das biografias atribuídas a estes quatro escritores contêm dedicatórias a um imperador, Diocleciano ou Constantino. Pólio e Vopisco não endereçaram suas composições a nenhum imperador, mas a amigos seus.

A data da composição também aparentemente não oferece dificuldade. E possível deduzir-se, através de informações contidas no texto, que certas Vitae foram compostas sob Diocleciano (284-305), outras sob Constâncio Cloro Augusto (305-306) e, finalmente, algumas durante o reinado de Constantino (306-337). Teria ocorrido, portanto, uma elaboração progressiva, no final do século III e no início do século IV, com a constituição definitiva da coletânea quando a última biografia foi escrita sob Constantino, após sua vitória sobre Licínio, entre 324 e 337.

Assim, a opinião geral dos eruditos sobre a H.A. até o final do século XIX poderia ser sintetizada desta forma: a H.A. é uma obra de grande valor documental, escrita por seis colaboradores, provavelmente não de uma só vez, mas gradualmente durante um período que cobre parte dos reinados de Diocleciano a Constantino.

A partir daquela época, todos estes conceitos passaram a ser debatidos extensamente. Como se explica o interesse despertado por uma obra 
com tais características, de estilo tão pobre, cujo conteúdo descai freqüentemente na trivialidade?

Pesquisadores deixam clara a sua importância dentro da historiografia latina. Lambrecht afirma: Elle est incontestablement notre meilleure source latine littéraire pour l'étude de l'histoire des $2^{e}$ et $3^{e}$ siècles (2). Chastagnol a classifica como "obra essencial", embora reconhecendo que ela coloca le probleme le plus irritant de toda a historiografia latina. Ela constitui a fonte literária mais abundante para o período que recobre, para o qual, na maioria dos casos, dispomos de escassa documentação. A sua importância aumenta na medida en que oferece numerosos informes sobre o. meio social dos autores, sobre a atmosfera política, espiritual e religiosa da época da redação (3). Momigliano concorda com este ponto de vista, pois afirma: The Historia Augusta is not only our most important source for Roman history from Hadrian to Diocletian, but also a significant document of late Roman religious and political thought (4).

Na última década do século passado teria início a publicação de estudos que provocariam uma reavaliação da obra dos S.H.A.. Inicialmente, temos um artigo no qual Mommsen estabelecia importante distinção entre as primeiras dezesseis Vidas, isto é, as de Adriano até Diadúmeno, classificando-as como major e minor (5). As vidas que ele qualifica como majores são aquelas dos imperadores que reinaram; as vidas minores são as dos césares e dos ustrpadores ou pretendentes (L. Élio César, L. Vero, Avídio Cássio, Pescênio Nigro, Clódio Albino, Geta e Diadúmeno).

Apresentar as biografias destas figuras menores é uma inovação da H.A. . Nelas abundam documentos transcritos; ora, a autencidade destes documentos foi contestada desde há muito; já em 1870, um trabalho mostrava que os documentos em Avídio Cássio, ostensivamente apresentados como cartas de Lúcio Vero, Marco Aurélio, de um prefeito do pretório, da imperatriz Faustina e do próprio Avídio Cássio, tinham sido indiscutivelmente compostos pela mesma pessoa. Investigações semelhantes produziram resultados análogos a respeito de documentos encontrados em outras biografias. Há na H.A. 150 cartas, discursos, decretos senatoriais e aclamações, cuja autenticidade dificilmente encontraria hoje defensores.

(2) - LAMBRECHTS, P., Le problème de l'Histoire Auguste. AC, 3, 1934, p. 514 .

(3) - CHASTAGNOL, A., Le problème de l'Histoire Auguste: état de la question. BHAC, 1963. Bonn, R. Habelt, 1964, p. 43-44.

(4) - MOMIGLIANO, A., "An unsolved problem of historical forgery The Scriptores Historiae Augustae", in: Secondo contributo alla Storia degli Studi Classici. Roma, 1960, p. 112.

(5) - MOMMSEN, Th., Die Scriptores Historiae Augustae. Hermes, 25, 1890, p. 246 ss. Apud BIRLEY, A. R., "The Augustan History", in: Latin Biography. New York, Basic Books, 1967, p. 121. 
As Vidas minores foram compostas por um processo que consiste em extrair das Vidas majores uma base mínima de fatos, e completá-las com pura ficção (6). Método análogo foi usado para as Vidas do século III, nos períodos sobre os quais a $\mathrm{H}$.A. não dispunha de fontes em que se basear.

As Vidas minores do século II e as de todas as personagens do século III (posteriores a Séptimo Severo) contêm uma tênue estrutura factual. Os "documentos" aparecem em maior número precisamente naquelas partes onde o autor da biografia sentiu necessidade de material extra para compensar a escassez de fontes históricas.

O debate sobre a H.A., entretanto, iniciou-se verdadeiramente apenas quando Hermann Dessau, num célebre artigo Über Zeit und Persönlichkeit der Scriptores Historiae Augustae, publicado em 1889 (7), colocou em dúvida, pela primeira vez, a opinião tradicional. Segundo a tese de Dessau, a H.A. não foi escrita na época em que ela induz o leitor a crer, ou seja, durante os reinados de Diocleciano, Constâncio Cloro e Constantino; teria sido composta num período posterior, aproximadamente entre 385 e 395. A obra seria uma fraude: os seis autores da H.A. não são realmente personagens históricas; foram criados pelo autor das biografias - um único autor, a quem Dessau designava como Fälscher.

$\mathrm{Na}$ argumentação em defesa da sua teoria, ele indicou, em primeiro lugar, uma série de nomes de personagens mencionadas na $\mathrm{H}$.A. que, aparentemente, demonstram o conhecimento de ou alusão a pessoas que viveram após a pretensa época da redação.

Em segundo lugar, Dessau provou a estreita dependência, principalmente de duas extensas passagens da H.A., em relação a obras cuja data é conhecida com precisão; estas obras são os "Césares", de Aurélio Vitor e o "Breviário da História Romana" de Eutrópio, publicados em 360 e 369 , respectivamente. Tais datas constituíam, portanto, um terminus post quem bem determinado para a composição da coletânea.

Dessau conseguiu demonstrar que evidentemente havia grande número de falsificações, embora aceitando que a H.A. apresentava um inegável fundo histórico. As invocações e alocuções dirigidas a Diocleciano e Constantino seriam somente artifícios destinados a iludir o leitor, fazendo-o acreditar que eram os imperadores reinantes quando a obra foi escrita, embora a composição tivesse ocorrido verdadeiramente na época teodosiana.

O artigo de Dessau desencadeou uma discussão da qual participaram os grandes nomes da época, tornando-se tema de debate nas revistas germânicas.

(6) - BARNES, T.D., The lost Kaisergeschichte and the Latin historical tradition. BHAC 1968/1969. Bonn, R. Habelt, 1970, p. 30 .

(7) - Hermes, 24, 1889, p. 337-392. 
Theodor Mommsen não podendo negar a evidência dos argumentos de Dessau e não desejando abandonar completamente a teoria tradicional, adotou uma posição intermediária. Continuou aceitando a antiga data da composição da H.A., mas afirmou sua crença numa reedição do Corpus das biografias, com adições e revisões - uma primeira vez em 330 e outra em fins do século IV (8). O fundo da obra seria autêntico, assim como o panegírico da dinastia constantiniana. Um primeiro compilador teria introduzido modificações, na época de Constantino, acrescentando as dedicatórias a este imperador. Sob Teodósio I, teriam sido interpoladas as passagens extraídas de Aurélio Vitor e Eutrópio, assim como as alusões a personagens coevas. Estava lançada a teoria dos Diaskeuasten, que hoje está completamente abandonada.

Em síntese, admitia a dependência da H.A. em relação aos empréstimos a Aurélio Vitor e Eutrópio, assim como as alusões a acontecimentos e personagens contemporâneos a Teodósio I; mas criticava Dessau por este não apresentar explicação para $\circ$ motivo da falsificação. Para Mommsen o cui bono? da falsificação permanecia uma questão sem resposta. Quanto à autoria, manifestava-se favoravelmente à pluralidade de autores.

Elimar Klebs combateu a hipótese de Mommsen (9), esforçando-se por provar que a H.A., Aurélio Vitor e Eutrópio derivavam todos de uma fonte comum, a chamada Kaisergeschichte (História Imperial) de Enmann, sem que houvesse ocorrido empréstimos diretos da H.A. em relação aos epitomadores.

Deixando de lado os detalhes, até 1926 estavam claramente delineadas duas correntes: a dos adeptos da teoria da falsificação tardia, seguindo a linha de Dessau e Otto Seeck; num segundo grupo, os defensores da tradição diocleciano-constantiniana, representada por E. Klebs, Hermann Peter, Gaetano de Sanctis, Charles Lécrivain e Léon Homo.

Em 1926, uma nova fase abria-se no debate com a publicação do livro de Norman H. Baynes, The Historia Augusta. Its date and purpose. Era uma tentativa de responder ao cui bono? mommseniano. Através de uma análise detalhada, Baynes acreditava haver descoberto uma tendência geral na H.A.: propaganda em favor das idéias políticas do imperador Juliano. A obra teria sido produzida durante o próprio reinado do Apóstata, nos anos de 362-63. Admitindo esta data de composição, não havia problema quanto ao tso do "Breviário" de Aurélio Vitor como fonte direta para a

(8) - MOMMSEN, Th., Die Scriptores Historiae Augustae. Hermes, 25, 1890 , p. $228-292$.

(9) - KLEBS, E., Rheinisches Museum, N.F. 45, 1890, p. 436-465. Apud LAMBRECHTS, P., $A C, 3,1934$, pp. 504-505. 
H.A. Quanto ao que considerava aparente uso de Eutrópio, Baynes explicava pela utilização da mesma fonte comum, que ele preferia chamar de Kaiser-chronik de Enmann. Considerava a H.A. um Volksbuch, um livro destinado ao grande público, escrito com a intenção de glorificar a pessoa de Juliano e de propagar suas idéias políticas e religiosas (10).

Anos mais tarde, outra obra viria marcar época. Werner Hartke, em 1940, apresentou uma tese que colocava a composição da H.A. por um único autor no período que seguiu a usurpação de Eugênio e a batalha do Frigidus em setembro de 394. Desenvolveu em duas obras vasta pesquisa sobre o ambiente político, literário e filosófico que deu origem à H.A. (11). Esta teria uma "tendência" política bem definida. Reconhecendo nela marcante simpatia pelos usurpadores, defende o ponto de vista de que a H.A. é um escrito de propaganda em favor de um usurpador da época de Teodósio I, Eugênio e de seus partidários, senadores romanos de orientação pagã. Teria sido redigida às pressas entre a derrota deste usurpador (6 de setembro de 394) e a morte de Teodósio I (17 de janeiro de 395). O objetivo seria sugerir ao imperador vitorioso clemência para com os rebeldes derrotados. Hartke desenvolveu a teoria de que a obra teria sido composta em 394 por um membro do círculo de Símaco: Nicômaco Flaviano Junior, antigo praefectus urbis de Eugênio; encontrando-se em desgraça, teria escrito camuflado sob seis pseudônimos, antedatando a obra. Finalmente, a H.A. teria utilizado tanto Aurélio Vitor quanto Eutrópio.

Henri Stern, por sua vez, levantou hipótese diversa (12). Segundo ele, o panegírico aos tetrarcas e à dinastia de Constantino é dirigido a Constâncio II, após a derrota de Magnêncio. A obra teria sido composta no momento em que Constâncio II, tendo assegurado o domínio sobre o império, chegava à Itália, preparando-se para punir aqueles que haviam apoiado os revoltosos. A data da composição ficaria entre $352-354$ e a autoria seria de um grupo de retores por encomenda de aristocratas romanos, temerosos das represálias do imperador.

Jacques Schwartz, em 1961, propôs fixar o trabalho de redação da H.A. no decorrer da própria usurpação de Eugênio (392-394), dentro do

(10) - BAYNES, N., The Historia Augusta. Its date and purpose. Oxford, Clarendon Press, 1926.

(11) - HARTKE, W., Geschichte und Politik im spätantiken Rom. Untersuchungen über die Scriptores Historiae Augustae. Klio, 45 (N.F. 32), 1940. Suas opiniốes foram ampliadas e diversificadas em Römische Kinderkaiser, eine Strukturanalyse römischen Denkens und Daseins. Berlin, 1951.

(12) - STERN, H., Date et destinataire de l'Historie Auguste. Paris, Belles Lettres, 1953. 
círculo de Sexto Petrônio Probo, sendo concluída em fins de 394, após a batalha do Frigidus (13).

No post-scriptum que acompanhou a republicação do seu artigo de 1961, Schwartz modifica sua posição, não mais admitindo que o redator final pertença ao círculo dos Anícios-Probos. Justifica-se alegando os progressos das pesquisas concernentes à H.A. (14) .

Uma nova abordagem do problema da H.A. foi criada por Santo Mazzarino (15). Demonstrou que uma tendência dominante da H.A. é a preocupação com o social e o econômico; a redação foi influenciada pelos interesse dos grandes proprietários da ordem senatorial romana.

Johannes Straub também reconhece na H.A. a tendência a favor dos usurpadores, assim como a apologia da sucessão por adoção e do paganismo. Para ele, a História Augusta foi concebida como uma apologia pagã da História: Il Mommsen domandava: 'cui bono?', cioè: perché questa falsificazione? Io risponderei: La Historia Augusta è una 'historia adversus Christianos' (16).

Straub e Mazzarino aceitam o terminus post quem de 394, mas tendem a situar a obra no início do século V, sob o reinado de Honório. Mazzarino, embora sem insistir sobre a questão da data, afirma: potremmo porre la Historia Augusta, grosso modo, nel periodo $419-421$ (17).

André Chastagnol aceita como limites cronológicos para composição as datas de 394 a 398; a publicação seria no fim de 397 e início de 398 na primeira parte do governo de Estilicão. Teria sido redigida após a vitória de Teodósio sobre Eugênio, num momento em que a propaganda pagã estava proibida. Concorda com Hartke, que orientou a investigação para o grupo ligado a Flaviano Junior; os autores pertencem aos meios senatoriais pagãos de Roma, talvez ao círculo de Símaco e de seu genro (18).

Philippe Horovitz considera a H.A. uma obra de propaganda anticristã, elaborada por um pagão fanático durante o reinado de Honório;

(13) - SCHWARTZ, J., Sur la date de l'Historire Auguste. Bulletin de la Faculté des Lettres de Strasbourg, 1961, pp. 169-176.

(14) - SCHWARTZ, J., Sur la date de l'Histoire Auguste. BHAC 1966/67. Bonn, R. Habelt, 1968, p. 99.

(15) - Aspetti sociali del quarto secolo. Roma, L'Erma, 1951.

(16) - STRAUB, Joh., "Le leggi di Severo Alessandro in materia di usura", in: COLLOQUIO PATAVINO SUlla HISTORIA AUGUSTA. Atti. Roma, L'Erma di Brestschneider, 1963, p. 20.

(17) - MAZZARINO, S., Il pensiero historica classico. Bari, Laterza, 1974. v. 3, p. 244; cf. também p. 214.

(18) - CHASTAGNOL, A., BHAC 1963, p. 50; 66. La prefecture urbaine à Rome sous le Bas-Empire. Paris ,Presses Universitaires de France, 1960. pp. 14-15. 
mais precisamente, situa-a em 407 ou na primeira metade de 408, num momento em que Roma era ameaçada por graves perigos externos (19).

Hoje, a datação tradicional diocleciano-constantiniana conta poucos seguidores, entre os quais a soviética E.M. Steyermann e A.H.M. Jones (20).

Arnaldo Momigliano prefere assumir uma atitude de prudente reserva: desejando acreditar numa falsificação post-constantiniana, considera, todavia, que ainda não foram encontradas provas irrefutáveis. Para ele, o problema da data da H.A. ainda não está solucionado (21).

A tendência atual dos estudiosos deste assunto é, no seu conjunto, a preferência pelas datas baixas, nos últimos anos de Teodósio ou no reinado de Honório. A maioria dos pesquisadores admite a falsificação e a maior parte das conclusões de $\mathrm{H}$. Dessau; um traço comum é a aceitação do terminus post quem de 390 , fixando a data da composição no período entre 392 e 423 (22).

Se o problema da datação gerou tanta controvérsia, a questão da autoria da H.A. constitui um outro eixo em torno do qual a discussão não é menor. Dessau, como foi referido acima, defendeu a tese de que um único autor compôs a H.A. Dois artigos dedicados especificamente ao problema, de P. White e de I. Marriott, parecem altamente elucidativos e suas conclusões merecem atenção.

No artigo, P. White propõe-se confirmar, contra E. Klebs, a tese de Dessau a favor da unicidade da autoria da H.A.. Ele desenvolve treze argumentos bastante convincentes, apoiado em citações do texto. Uma das provas mais concretas é que os mesmos temas e os mesmos artifícios de composição aparecem nas biografias aparentemente redigidas pelós diferentes scriptores. Importante observação é a de que o tom da H.A. varia de uma parte a outra conforme se modifica a relação entre o autor e as fon-

(19) - HOROVITZ, Ph., "Essai sur la date de la publication et le but de l'Histoire Auguste". in: Mélanges d'Archéologie et d'Histoire offerts à André Piganiol. Paris, S.E.V.P.E.N., 1966, t. 3, pp. 1743-48.

(20) - STEYERMANN, E.M., Programmes politiques à l'époque de la crise du IIIe siècle. Cahiers d'Histoire Mondiale, 4: 324-327, 1958. - Die S.H.A. als Geschichtesquelle Bibliotheca Classica Orientalis, 5, 1960, col. 93-100. Apud CHASTAGNOL, A., BHAC 1963, p. 51. JONES, A.H.M., The later Roman Empire. Oxford, 1934. v. 3, p. 1, n. 1.

(21) - MOMIGLIANO, A., op. cit., p. 105-143.

(22) - As pesquisas atuais têm sido publicadas pela editora Rudolf Habeit, de Bonn, na quarta série da coleção "Antiquitas". Foram editadas as atas dos colóquios sob o título de Bonner Historia - Augusta Colloquium. Em 1963, em Pádua, ocorreu um colóquio do qual publicou-se: Atti del Colloquio Patavino sulla H.A. (Roma, 1964). 
tes por ele utilizadas. Quando reproduz fontes latinas, mostra-se relativamente sóbrio e factual; quando improvisa seu próprio material, devido à escassez ou ausência de fontes, torna-se "irresponsável e bombástico". Este seria o fator determinante da variedade de estilos na H.A., e não a existência de seis autores. Concluindo, segundo White: it seems convenient to believe that one man wrote the Historia Augusta (23).

Num estudo mais recente e com características diversas, Ian Marriott aplicou o uso de computadores na análise estilística com o objetivo de resolver esta questão da autoria. Os seis "autores", aos quais as partes da obra são atribuídas, são conhecidos exclusivamente através da H.A.; não existem outras obras deles que permitam uma comparação. O estudo de Marriott procurou, então, verificar as diferenças e similaridades entre os seis.

Comparando os grupos de biografias, concluiu que internamente a H.A. é homogênea; os seis "autores" não apresentam diferença significativa entre si. A diversidade dentro da obra é baseada não na pluralidade de autores, mas nos diversos tipos de composição. Sua conclusão final é idêntica à de White: singular autorship for the Historia Augusta (24).

\section{A COMPOSIÇÃO DA VITA ALEXANDRE SEVERI}

A H.A. provém de um meio social bem definido: a aristocracia senatorial da cidade de Roma, da qual expressa os interesses políticos, sociais e econômicos. A veneração pelo Senado é uma constante da obra, perceptível em inúmeras passagens da Vita Alexandri (25).

Tópicos já presentes na literatura foram utilizados e desenvolvidos pela H.A. . Ela demonstra evidente aversão pela sucessão imperial hereditária, retomando os já tradicionais ideais do optimus princeps antoniniano. De modo mais específico, concentra sua crítica sobre os principes pueri, ignorantes dos assuntos públicos e instrumentos passivos dos maus conselheiros; entre estes, os mais insistentemente atacados são os eunucos.

A Vita Alexandri mostra qual deve ser a atitude do bom príncipe em relação aos eunucos (26). Severo Alexandre, embora fosse puer ao assumir - governo, soube reduzir o poder e a influência por eles adquirida sob Heliogábalo. Afastou-os da aula, relegando-os a funções domésticas e im-

(23) - WHITE, P., The authorship of the Historia Augusta. JRS, 57, 1967,

(24) -MARRIOTT, Ian, The authorship of the Historia Augusta: two computer studies. JRS, 69, 1979, p. 74.

(25) - Alex. Sev., 1,2-5; 10,7; 18,2; 19,1-4; 21,5; 24,1; 43,1-2; 46,5; 49,2; 52,2.

(26) - Alex. Sev. 23,4-7; 34,3; 45-4-5; 66,3-67,1. 
pediu que ocupassem posições como intermediários e controlassem o acesso ao príncipe.

O biógrafo critica abertamente o gênero de corte oriental que a centralização do poder no século IV desenvolvia em Roma. Os eunucos exploravam seu contato cotidiano com o imperador para adquirir poder de fato; a sua ascendência pessoal era maior sob imperadores débeis ou imaturos. Funcionavam como uma barreira, aumentando o isolamento do príncipe; filtravam as informações que deviam chegar ao soberano e alteravam as suas decisões. A sua influência era inversamente proporcional à do círculo dos amici oriundos das camadas mais elevadas da sociedade romana. O príncipe-ideal devia favorecer estes amici, particularmente os do meio senatorial.

A Vita tem consciência do enorme perigo que os eunucos representam para os senadores, e não exagera ao afirmar que eles podem provocar a queda do príncipe. Não se trata de retórica vazia, mas da expressão da irremediável divergência entre a aristocracia senatorial de Roma e um Estado que a exclui. Os senadores que cultuam as antigas tradições não querem a sujeição a um príncipe que vive more gentium aut regum Persarum (ALEX. SEV. 66,3).

Em veemente oração dirigida diretamente ao imperador Constantino (ALEX. SEV. 65,ss.), a Vita Alexandri o adverte contra os maus conselheiros que podem influenciar um príncipe, principalmente os eunucos.

$\mathrm{Na}$ composição da Vita são desenvolvidos ainda outros temas:

1 - o nomen Antoninorum, em torno do qual foram compostos um discurso imperial e aclamações senatoriais (27);

2 - o imperador árabilis. Um atributo convencional do bonus imperator (28);

3 - aversão aos fures iudices (29) e aos ladrões em geral (30), aos quais são reservadas punições extremamente severas;

4 - "vendedores de falsas promessas" (31), item sobre o qual é criado o episódio de Vercônio Turino, punido com pena capital (fumo punitur qui vendidit fumum);

5 - a "severidade" do imperador (32).

(27) - Alex. Sev., 1,1; 2,2; 7,1-6; 10,6.

(28) - Alex. Sev., 4,5;48,5; 50,3; 59,1.

(29) - Alex. Sev., 15,4; 17,1-2.

(30) - Alex, Sev., 17,3-4; 18,2; 18,4-5; 22,6; 28,2-5.

(31) - Alex. Sev., 23,8; 35,5 - 36,3; 67,2.

(32) - Alex. Sev., 12,4-5; 25,2; 52,3; 59,4-6; 64,3. 
O redator da Vita Alexandri afeta grande preocupação com a verdade (33) : Proclama a superioridade da História sobre a voz corrente do povo: ... ne quis vulgi magis famam sequeretur quam historiam, quae rumore utique vulgi verior reperitur (ALEX. SEV. 48,8).

A Vita Alexandri Severi alude freqüentemente a escritores, historiadores e biógrafos cujo testemunho invoca ou cuja opinião contesta. Não é raro surgirem comparações críticas entre duas versões do mesmo assunto; por vezes o biógrafo aconselha o leitor a consultar as obras deste ou daquele autor sobre algum ponto particular.

Tais recursos criam a impressão de que a biografia resultou de intensa pesquisa em grande número de fontes. Torna-se necessário, portanto, um estudo minucioso das fontes reais, o que poderá lançar certa luz sobre o método de composição.

Há fontes que foram efetivamente usadas e que como tal são mencionadas. Em outros casos, porém, cabe uma distinção preliminar: nem todas as fontes utilizadas o autor citou e de algumas citadas é improvável a existência.

Examinemos o caso de Herodiano, cuja obra foi utilizada e que é citado explicitamente em Alex. Sev. 52,2 e 57,3. Comparando as passagens de ambas as obras, torna-se claro o seu uso na Vita Alexandri Severi:

H.A., Alex. Sev. 52,2

Seu império, embora duro e severo, foi chamado de incruento, pois nenhum senador foi condenado, como afirma o escritor grego Herodiano na história do seu tempo.

HEROD. VI, 1,7

Governou durante quatorze anos sem derramar sangue inocente.

HEROD. $V I, 9,8$

Assim morreu Alexandre, após quatorze anos de reinado, durante os quais não mereceu nenhuma censura de seus súditos e não fez derramar sangue inocente.

A segunda passagem refere-se à campanha contra os persas:

H.A., Alex. Sev. 57,3

Afirmoū-se também que ele perdeu seu exército pela fome, frio e doença; esta é a versão dada por Herodiano, mas contrária à crença da maioria.

(33) - Alex. Sev., 3,5; 64,4; 65,3. 
HEROD. VI, 6,3

Alexandre, tendo também perdido muitos homens, conduziu à Antioquia as tropas que permaneceram com ele; tudo isto o tornou impopular e produziu grande desânimo no exército. Ele havia errado os seus cálculos e o destino the havia sido contrário; por diferentes infortúnios: as doenças, o frio, a derrota, perdeu a maior parte dos três exército entre os quais havia dividido as suas forças.

Em outros casos, embora a fonte seja evidentemente Herodiano, o nome deste não é citado. A informação é atribuída a quidam litteris (Alex. Sev. 25,1), ou prefere-se multi dicunt (Alex. Sev. 59,7-8), ou omite-se simplesmente a fonte (Alex. Sev. 61,8).

H.A., Alex. Sev. 25,1

Alguns escritores afirmam que seu reinado foi incruento, o que é inexato. Contra Herodiano VI, 1,7 e VI, 9,8 (ver supra).

H.A., Alex. Sev. 59,7-8

Muitos dizem que ele foi morto por alguns recrutas enviados por Maximino, a quem tinham sido confiados para seu treinamento, e muitos outros dão versões diferenttes. Concordam, contudo, que foram soldados que o mataram, insultando-o, chamando-o de criança e sua mãe de avarenta e cobiçosa.

HEROD. $V I, 8,2$

Devido à experiência militar que disto resultava, Alexandre havia confiado a Maximino o comando de todos os novos recrutas. para que os adestrasse e os tornasse aptos para combater.

HEROD. VI, 9,4

Outros acusavam a mãe de cupidez e de avareza, afirmando que tha havia suscitado o ódio contra Alexandre devido a sua mesquintesz e relutância em conceder donativos.

H.A., Alex. Sev. 61,8

Todos os aparatos militares, que Maximino mais tarde conduziu a Germânia, eram de Alexandre e eram potentes graças aos armênios, osdroenos, partos e homens de todas as raças.

HEROD. VII, 2,1

... numerosos mouros, arremessadores de dardo; arqueiros osdroenos ou armênios (alguns como súditos, outros como aliados); enfim, uin certo número de partos, que na qualidade de mercenários serviam aos romanos, ou como desertores ou como prisioneiros de guerra. Um forte exército já havia sido precedentemente concentrado por Alexandre e Maximino o aumentou, melhorando também o seu nível de adestramento. 
Embora Dexipo apareça como fonte principal somente para o período compreendido entre 238 e 270 (34), a H.A. utiliza uma passagem deste autor sobre as relaçôes de parentesco de Severo Alexandre:

$$
\text { H.A., Alex. Sev. 49,3-5 }
$$

Dexipo diz que Alexandre casou com a filha de um certo Macrino a quem nomeou César; mas quando Macrino tentou matá-lo à traição, Alexandre, descobrindo o conluio, fez matar Macrino e também repudiou a mulher.

O mesmo autor diz que Antonino Heliogábalo era tio paterno de Alexandre e não filho da irmã da mãe.

H.A., Alex. Sev. 64,4-5

Dizem, além disso, que ele não era primo de Heliogábalo. Para aceitar a minha versão, que leiam os historiadores daquele tempo, particularmente Acólio, que também escreveu sobre as viagens deste príncipe.

Não cabe discutir a inexatidão da versão de Dexipo quanto ao casamento de Severo Alexandre; registre-se somente o uso pela V.A.S. da versão de Dexipo, a qual aliás tem pontos comuns com a de Herodiano (VI, 1,9-10).

Quanto ao parentesco entre Severo Alexandre e Heliogábalo, a V.A.S . não aceita a informação de Dexipo, contrapondo outra, correta e atribuída a Acólio. Contudo, a crítica dirigida a Dexipo é sem fundamento. Jardé encontrou a explicação para o pretenso erro imputado ao historiador grego: na verdade, o autor da Vita compreendeu mal a palavra grega anepsiós, que no grego clássico significa "primo", mas tardiamente assumiu o significado de "sobrinho". Ele não percebeu a diferença entre a língua de seus contemporâneos e aquela que Dexipo escrevia (35).

Examinando o texto da V.A.S., verificamos que o escritor mais citado é Mário Máximo; sua obra é mencionada em:

H.A., Alex. Sev.

5,4 - Como Mário Máximo narra na biografia de Severo, ...

21,4 - como disse Mário Máximo na biografia de muitos príncipes...

30,6 - o tetrafármaco de Adriano, do qual Mário Máximo fala na sua obra, quando relata a vida de Adriano.

(34) - BARNES, T. D., The sources of the Historia Augusta. Bruxelles, Latomus, 1978, pp. 109; 111; 125.

(35) - JARDE, A., Études critiques sur la vie et le règne de Sévère Alexandre. Paris, E. de Boccard, 1925, p. 5. 


\begin{abstract}
48,6 - Sei que o povo atribui o incidente que narrei a Trajano, mas Mário Máximo não faz menção em sua biografia de Trajano...

65,4 - Pois é bem conhecido por vossa Piedade, uma vez que foi lido na obra de Mário Máximo...
\end{abstract}

Este biógrafo deve, com toda probabilidade, ser indentificado com uma personagem cuja carreira senatorial é conhecida através de epígrafes, L. Mário Máximo Perpétuo Aureliano. Filho do procurador L. Mário Perpétuo, ingressou no Senado sob Cômodo, foi consul suffectus talvez em 198 ou 199, procônsul da África e da Ásia, nomeado prefeito urbano em 217, em 223 foi designado consul iterum ordinário por Severo Alexandre (36). Admite-se geralmente que tenha escrito durante o reinado deste imperador uma continuação dos Doze Césares de Suetônio, ou seja as vidas de doze imperadores, de Nerva até Heliogábalo; deve ter alcançado grande notoriedade e sua obra, hoje perdida, era muito difundida na época de Amiano Marcelino (XXVIII, 4,14). Esta fama pode talvez explicar o grande número de citações nos S.H.A. em geral e na Vita Alexandri Severi em particular (cinco vezes).

Ora, em nenhuma destas passagens da V.A.S. o biográfo está se referindo a Severo Alexandre. Três delas estão relacionadas com imperadores anteriores: Séptimo Severo, Adriano e Trajano $(5,4 ; 30,6 ; 48,6)$. Em 21,4, Máximo é lembrado não em relação a uma importante medida tomada por Severo Alexandre, mas à situação anterior, sob os reinados de seus antecessores. Em 48,6-7, aparece claramente a contraposição entre os biógrafos de Trajano $(48,6)$ e os de Severo Alexandre $(48,7)$; entre estes últimos, não figura o seu nome. Na dedicatória dirigida a Constantino $(65,4)$ afirma-se que este imperador lera a sua obra.

No artigo sobre Mário Máximo, Barbieri afirma: che le vite di Mario Massimo si estendano forse anche a quella di Severo Alessandro mi sembra di poter escludere in base all'analisi delle citazioni di M.M. in questa biografia della H.A. (37).

Em conclusão, a biografia de Severo Alexandre não é derivada de Mário Máximo, embora este tenha sido uma das fontes para a composição de Vitae precedentes.

Passemos ao exame de possíveis fontes não citadas explicitamente.

Em certas passagens a Vita apresenta estreita semelhança com Aurélio Vitor e Eutrópio.

(36) - BARBIERI, G., L'albo senatorio da Settimio Severo a Carino (193-285). Roma, 1952, p. 219, n.r. 1110.

(37) - BABIERI, G., Mario Massimo. RFIC, 32, 1954, p. 65. JARDÉ con. corda com esse ponto de vista. (Etudes critiques..., pp. 111-113). 
Se desde 1889, Dessau já postulava a utilização direta dos Caesares de Aurélio Vitor pela H.A., este fato hoje é admitido como comprovado por autores como Barnes, Chastagnol e R. Syme.

A H.A. pode também ter utilizado o Breviarum de Eutrópio. Mas o estilo deste é menos pessoal e, portanto, a comprovação de empréstimo torna-se mais difícil.

As passagens da Vita Alexandri Severi que demonstram o conhecimento que a H.A. tinha da obra de Aurélio Vitor são:

Alex. Sev. 26,5-6 C Caes. 24,6 - a prefeitura do pretório de Paulo e Ulpiano

Alex. Sev. 59,6 < Caes. 24,4 - morte de Severo Alexandre na Britânia

Alex. Sev. 24,4 < Caes. 28,6-7 - prostituição masculina

A primeira passagem refere-se aos juristas Paulo e Ulpiano e à nomeação deles para o cargo de prefeito do pretório:

Paulum et Ulpianum in magno honore habuit, quos praefectos ab Heliogabalo alii dicunt factos, alii ab ipso. Nam et consiliarius Alexandri et magister scrinii Ulpianus fuisse perhibetur (H.A., Alex. Sev. 26,5-6).

Segundo a H.A., alguns dizem que Heliogábalo nomeou-os prefeitos do pretório; outros, o próprio Severo Alexandre. Ora, a primeira alternativa encontra-se nos Caesares de Aurélio Vitor; a parte inicial da frase, até factos é inspirada em:

Domitium Ulpianum, quem Heliogabalus praetorianis praefecerat, eodam honore retinens Paulloque inter exordia patriae reddito... (Aur. Vit., Caesares 24,6).

Após factos a V.A.S. reproduz quase literalmente o texto de Eutrópio, o qual coloca a carreira dos dois personagens sob Severo Alexandre:

Adsessorem habuit vel scrinii magistrum Ulpianum, iuris conditorem (Eutr. VIII, 23).

Há, portanto, aparentemente, a utilização sucessiva de Vitor e de Eutrópio pela H.A.. Existem pontos de semelhança entre o relato de ambos, mas é também evidente que se dois epitomadores usaram a mesma fonte comum, interpretaram-na em sentidos diferentes. A H.A. coloca em destaque justamente esta divergência entre os dois historiadores; demonstra assim que teve acesso não somente à provável fonte comum, 
mas conhecia diretamente pelo menos o autor que se afastou desta fonte (38).

$\mathrm{Na}$ segunda passagem, é indicado o local do assassinato de Severo Alexandre:

In Britannia, ut alii volunt in Gallia, in vico cui Sicilia nomen est. (H.A., Alex. Sev. 59,6).

Em Aurélio Vitor encontra-se:

... vico Britanniae, cui vocabulum Sicilia, ... (Aur. Vit., Caesares $24,4)$.

Eutrópio informa que o episódio ocorreu na Gália:

periit in Galia militari tumultu (Eutr. VIII, 23).

Chastagnol comparou os textos da H.A. e de Aurélio Vitor a respeito da Campanha da Germânia:

H.A., Alex. Sev. 59

Aur. Vit., Caesares 24

1 - Ad Germanicum bellum profectus 2 - In Galliam maturrime contendit, est... quae Germanorum direptionibus ten-

2 - Erat autem gravissimum rei p. atque ipsi, quod Germanorum vastationi-3 - Ibi tumultuanttes legionum plerasque bus Gallia diripiebatur... constantissime abiecit...

4 - Sed cum ibi quoque seditiosas legio-4 - Nam tantae severitatis vim milites nes comperisset, abici eas praecepit inhorrescunt unde etiam Severi cog-

5 - Verum Gallicanae mentes, ut sese habent durae ac retorridae et saepe imperatoribus graves, severitatem hominomentum accesserat), agentem ca* su cum paucis vico Britanniae cui nis nimiam... vocabulum Sicilia, trucidavere

6 - Denique agentem eum cum paucis in Britannia... in vico cui Sicilia nomen est..., cum severum principem pati non possent, occiderunt

Desta comparação, conclui-se que o texto da H.A. copiou Aurélio Vitor no essencial, mas usou Eutrópio para completar ou corrigir os Caesares.

Em Eutrópio aparece tumultuantes legiones integras exauctoravit; isto confirma que ele utilizou Aurélio Vitor (Caes. 24,3) ou a sua fonte.

(38) - CHASTAGNOL, A., L'utilisation des "Caesares" d'Aurelius Victor dans l'Histoire Auguste. BHAC 1966/67. Bonn, R. Habelt, 1968, p. 60. 
Mas a H.A. ao insistir mais uma vez na contradição que há entre Aurélio Vitor e Eutrópio, demonstra novamente que os conhecia diretamente e não apenas através de uma fonte comum (39).

Barnes concorda que a diferença de opinião sobre o lugar do assassinato em V.S.A., 59,6 demonstra indubitavelmente o conhecimento de Vitor (40).

Em Alex. Sev. 24,4 há outro empréstimo tomado aos Caesares de Aurélio Vitor $(28,6-7)$ numa passagem relativa à prostituição masculina:

Habuit in animo ut exsoletos vetaret, quod postea Filippus facit, sed veritus est ne prohibens publicum dedecus in privatas cupiditates converteret, cum homines inlicita magis prohibita poscant furore iactati (H.A., Alex. Sev. 24,4).

A História Augusta encontrou a informação sobre a medida tomada por Filipe o Árabe em Aurélio Vitor, Caesares 28,6-7:

Imperator Philippus... usum virilis scorti removendum honestissime consultavit. Verumtamen manet: quippe condicione loci mutata, peioribus flagitiis agitatur, dum avidius periculosa quibusque prohibentur mortales petunt.

("O imperador Filipe... tomou a decisão muito virtuosa da proibir a atividade dos prostituídos masculinos. Entretanto ela subsiste; e, apesar das novas regulamentações de lugar, deu origem a torpezas ainda mais vergonhosas, pois os homens desejam mais avidamente aquilo que é perigoso e proibido").

Aurélio Vitor após relatar a ação de Filipe, acrescentou uma reflexão sua, pessoal, sobre a propensão dos seres humanos em desafiar as proibições. O biógrafo de Severo Alexandre na H.A. utilizou as duas frases de Aurélio Vitor: afirma que Severo Alexandre já havia cogitado em tomar a mesma decisão que Filipe tomou efetivamente mais tarde, e que desistiu de fazê-lo; acrescentou então, como justificativa, a mesma reflexão moral que Vitor emite ao constatar que a regulamentação de Filipe fora ineficaz.

A autor de Vita cometeu abertamente uma falsificação. Ele copiou Aurélio Vitor, mas deformou seu pensamento de modo proposital; este caso nos revela inclusive o método de composição do autor (41).

(39) - Idem, p. 61.

(40) - BARNES, T. D., BHAC 1968/69, p. 37.

(41) - CHASTAGNOL, A., Zosime II, 38 et l'Histoire Auguste. BHAC 1964/65. Bonn, R. Habelt, 1966, p. 54 ss.; Recherches sur l'Histoire Auguste. 
Na V.A.S. encontra-se uma frase muito semelhante à de Eutrópio: In matrem Mammaeam unice pius fuit (H.A., Alex. Sev. 26,9). In Mammaeam matrem suam unice pius (Eutr. VIII, 23).

Para Chastagnol, a H.A. copiou Eutrópio (42). Mas Barnes prefere a hipótese de que neste caso a fonte tenha sido a Kaiser Geschichte, uma vez que Jerônimo usou as mesmas palavras e na mesma ordem que a H.A.: in matrem Mammaeam unice pius fuit (43).

A leitura de Aurélio Vitor e Eutrópio demonstra que os dois epitomadores do século IV usaram de uma fonte comum que se revela também em certas passagens da H.A. e em outros escritores.

Em 1884, Alexander Enmann afirmava a existência de uma Geschichte der römischen Kaiser (44). Ele reconstruiu hipoteticamente esta obra perdida, através de textos mais ou menos similares encontrados na H.A., nos Caesares de Aurélio Vitor, no Breviário de Eutrópio, na Epitome de Caesaribus e na História de Zósimo-Eunápio.

A Kaisergeschichte (K.G.) de Enmann era constituída por uma série de biografias breves. Para cada uma, Enmann identificou um esquema, condensado em muito poucas linhas:

$$
\begin{aligned}
& 1 \text { - o nome do imperador e origem, uma obsertvação sobre a vida } \\
& \text { precedente (não a carreira detalhada), o lugar da proclamação no } \\
& \text { caso de ter chegado ao poder através de uma rebelião; } \\
& 2 \text { - guerras contra bárbaros e pretendentes; } \\
& 3 \text { - obras públicas, legislação e caráter do reinado; } \\
& 4 \text { - o lugar e a forma da morte do imperador, local do sepultamento, } \\
& \text { homenagens póstumas e duração do seu reinado. }
\end{aligned}
$$

Como é possível estabelecer os casos em que a História Augusta usou a K.G.? Partimos do fato de que a H.A. conhecia Vitor e Eutrópio. Contudo, se uma passagem da H.A. apresenta grande semelhança com eles ou com um deles, mas inclui detalhes autênticos omitidos por estes, então

Bonn, R. Halbelt, 1970, p. 9. SYME, R., Ammianus and the Historia Augusta. Oxford, Claredon Press, 1968, p. 107. BARNES, T. D., The sources..., p. 95; BHAC $1968 / 69$, p. 32 .

(42) - CHASTAGNOL, A., BHAC 1966/67, p. 60 . $1968 / 69$, p. 36.

(44) - ENMANN, Alexandre, Eine verlorene Geschichte der römischen Kaiser. Philologus, Suppl. IV, 1884, p. 335-501. Apud CHASTAGNOL, A., BHAC 1966/67. p. 59. n⿳ 22. BARNES, T. D., The sources..., p. 91, $\mathrm{n}^{\circ} 9$. 
os dados adicionais derivam da fonte comum, a K. G. . Em segundo lugar, se houver exata coincidência entre a H.A. e Jerônimo, isto deve ser atribuído a terem ambos copiado independentemente a K.G.; Jerônimo deve ter utilizado a K.G. na sua crônica, mas não há indícios de que a H.A. o tenha conhecido.

Baseado nestes princípios, Branes selecionou três passagens da Vita Alexandri Severi que considera derivadas da K.G.:

cunctis hominibus amabilis (H.A., Alex. Sev. 4,5).

omnibus amabilis (Jerônimo, GCS XLVII, 215).

thermas nominis sui iuxta eas quae Neronianae fuerunt, aqua inducta quae Alexandriana nunc dicitur (H.A., Alex Sev. 25,3). texto:

Eutrópio dá também informação sobre as termas, mas em outro con-

Is aedificavit Romae thermas quae, ante Neronianae dictae, nunc Alexandrinae appellantur (Eutrópio VII, 15,2).

Jerônimo cita-as (GCS XLVII, 215).

O terceiro caso é de Alex. Sev. 26,9 < Eutrópio VIII, 23 (vide supra).

Estas relações entre Aurélio Vitor, Eutrópio e a H.A. são importantes para a datação desta última. Daí decorrem divergências entre os autores, cujas posições podem, em linha geral, serem agrupadas desta forma:

1 - uns (45) explicam as semelhanças textuais como derivação independente devida à utilizaçãa de fonte comum, que a H.A. teria reproduzido.

2 - outros consideram as semelhanças resultado do uso direto pela H.A. dos Caesares e do Breviarium. Alguns, como W. Hartke e T. Damsholt, tendem a negar mesmo que a H.A. tenha utilizado a K.G. (46). Chastagnol coloca claramente suas conclusões: "deve-se reconhecer que Aurélio Vitor e Eutrópio foram as fontes diretas da H.A. mais frequientemente do que se imaginava outrora". Em seguida, deduz as implicações óbvias: "Decorre destas pesquisas que a H.A. deve ser posterior a 360 ,

(45) - KLEBS, E., Rheinisches Museum, N.: F. 45, 1890, p. 436 ss. Foi o primeiro a adotar essa linha conservadora. Apud BARNES, T. D., The sources..., p. 91 .

(46) - DAMSHOL, T., Classica et Mediaevalia, 25, 1964, p. 146 ss. HARTKE, W., Klio, 45, 1940, p. 12 ss. Apud BARNES, T. D., The sources..., p. 91. 
data do término dos Caesares de Aurélio Vitor, e a 369-370, ano que viu a publicação do Breviário de Eutrópio" (47).

A conclusão de Mazzarino parece-nos a mais aceitável no que se refere às fontes (sem discutir a datação):

\begin{abstract}
"fermo restando che la Historia Augusta, scritta (come tendiamo a ritenere) sotto Onorio, doveva aver presente, di questi Latini scriptores, soprattutto la più ampia 'Kaisergeschichte' di Enmann ma anche poteva consultare scritti minori como il liber di Aurelio Vittore e anche Eutropio" (48).
\end{abstract}

Resta verificar ainda, entre as fontes citadas na Vita, várias personagens apresentadas como biógrafos.

Aurélio Filipo (Alex. Sev. 3,2), Acólio (Alex. Sev. 14,6; 48,7; 64,5), Encólpio (Alex. Sev. 17,1; 48,7), Septímio (Alex. Sev. 17,2; 48,7), Gar-! gílio (Alex. Sev. 37,9) são mencionados como tendo escrito sobre a vida de Severo Alexandre.

Como biógrafos de Trajano, além de Mário Máximo, aparecem mais três nomes: Fábio Marcelino, Aurélio Vero e Estácio Valente (Alex. Sev. 48,6).

Uma dúvida se impõe: estes escritores tiveram existência real, ou são imaginários? Jardé já considerava válida a suspeita de que haviam sido imaginados pelo autor (49). Hoje, no atual estágio em que estão os estudos sobre a H.A., é notória a sua propensão à fraude e à criação dos bogus names (50). Ora, esses autores não são registrados em nenhuma outra fonte; sem dúvida são criação da própria História Augusta.

Uma observação deve ser feita, entretanto, no caso de Acólio; citado também na vida de Aureliano 12,4 como magister admissionum na época de Valeriano, poderia talvez ser identificado como a personagem de uma inscrição grega de Sardes, governador da Lídia em 260. Mazzarino parece aceitar a existência histórica deste Acólio (51), que forneceu uma notícia correta sobre o fato de Severo Alexandre ser primo de Heliogábalo, segundo a V.A.S. .

As pesquisas sobre estes "biógrafos" são de pouca utilidade, pois foram usados apenas para detalhes ínfimos e algumas vezes suspeitos.

(47) - CHASTAGNOL, A., Recherches..., p. 10.

(48) - MAZZARINO, S., Pensiero storico..., p. 237.

(49) - JARDE, A., Etudes critiques..., p. 103.

(50) - SYME, R., The bogus names in the Historia Augusta. BHAC 1964/65.

Bonn, R. Habelt, 1966 , p. 257-72.

(51) - MAZZARINO, S., Pensiero storico..., p. 280. 
Realmente, seus nomes estão ligados a passagens pouco relevantes da Vita. Parecem ter sido criados pelo autor a fim de emprestar um ar de autenticidade a trechos oriundos igualmente da sua imaginação.

Quanto às fontes principais que forneceram a base factual para a elaboração da Vita, o autor preferiu silenciar; conforme o uso dos historiadores latinos, ele não se preocupou em indicar a verdadeira proveniên. cia de suas informações.

Em muitas passagens, o autor da Vita refere-se às fontes de forma muito genérica, usando expressões vagas:

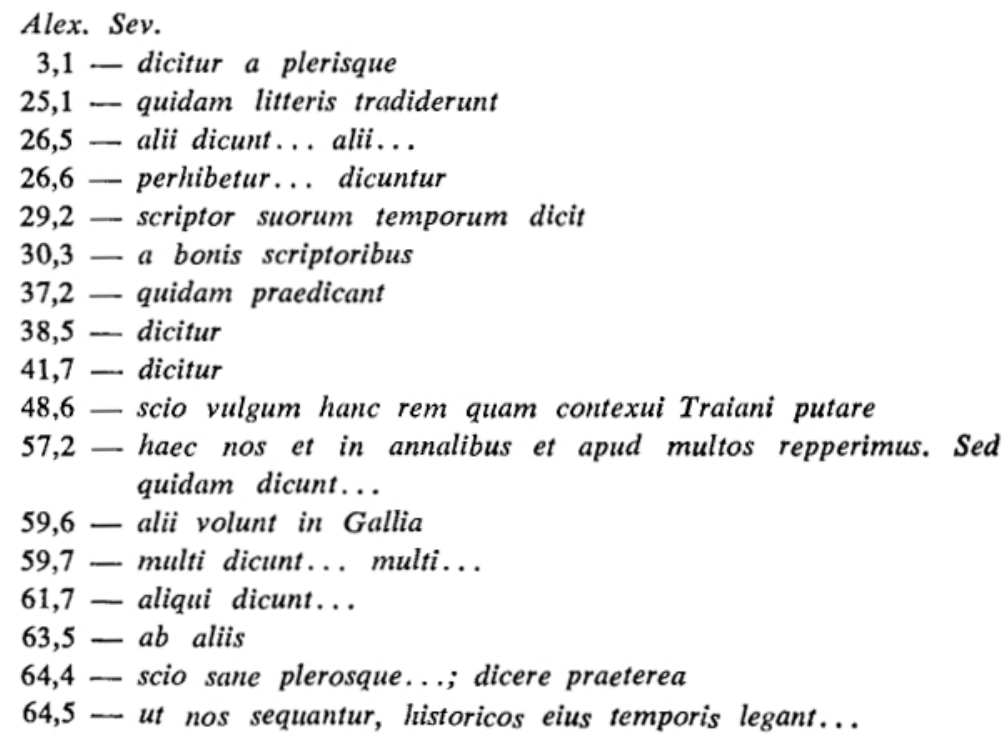

Em alguns casos, o autor usa estas formas para referir-se, de modo indireto, a Herodiano ou aos epitomadores. Na maioria das vezes, entretanto, é somente um mecanismo para dar credibilidade à narrativa .

A H.A. dispunha de escassas fontes literárias válidas para o reinado de Severo Alexandre; o autor supriu esta falha usando a imaginação.

The Alexandre is fiction cast into a simple framework of fact (52), segundo Barnes; este autor selecionou as passagens que, a seu critério, compõem o conteúdo factual da Vita (53). Nós o utilizamos, embora com alterações.

(52) - BARNES, T. D., BHAC 1968/69, p. 43.

(53) - BARNES, T. D., The sources..., p. 57-59. 
O objetivo não foi o de meramente selecionar os "dados seguros", separando-os os "dados duvidosos", para utilizar apenas os primeiros. Ao contrário, interessa-nos o que foi livremente criado pelo redator da V.A.S. .

Aqui selecionamos as passagens que a H.A. tomou de outras fontes literárias; a partir delas é possível deduzir, por exclusão, o que foi composto pela imaginação do autor. Fatos confirmados por testemunhos epigráficos, arqueológicos ou numismáticos também são incluídos.

Consideramos, portanto, este o conteúdo factual da Vita Alex. Sev.:

1,1-2 Cf. Aurélio Vitor, Caesares 24,1; Eutrópio, Breviarium VIII, 23. Alexandre nasceu em Arce, era primo de Heliogábalo e fora proclamado César em junho de 221 (Feriale Duranum II, 16-7).

4,5 Provém da K.G. 'cunctis hominibus amabilis", corresponde a "omnibus amabilis" em Jerônimo (GCS XLVII, 215).

12,5 Cf. Aurélio Vitor, Caesares 24,3; Eutrópio, Breviarium VIII, 23; Jerônimo (GCS XLVII, 215). A severidade e o licenciamento de legiôes amotinadas aparece novamente em 59,4-5.

24,3 Obras de restauração. A restauração do Coliseu, isto é, do amphitheatrum Flavium é comprovada por moedas de 223 (B.M.C., R. Emp. VI, p. 54; pp. 129 e segs.). Restauração de teatro: ver 44,7 .

25,1-2 Refutação de Herodiano VI, 1-7; 9,8. Cf. Aurélio Vitor, Caesares 24,4: nam, cum tantae severitatis vim milites inhorrescunt (unde etiam Severi cognomentum acesserat)...

25,3 A contrução de termas é atestada por outras fontes. Eutrópio afirma que Nero construiu as termas quae, ante Neronianae dictae, nunc Alexandrinae appellantur (Breviarium VII, 15,2). Jerônimo (GCS XLVII, 215), o Cronógrafo de 354 (MGH Auct. Ant. IX, 147) e P. Oxy. 412, Col. II, linhas 63 e segs. registram a construção de termas por Alexandre. Aqueduto: Polêmio Sílvio (MGH Auct. Ant. IX, 546).

25,6 Cf. H.A. Vita Heliogabali 17,9.

26,1 Moedas fazem referência a cinco ocasiões nas quais Severo Alexandre concedeu liberalitates (BMC, R. Emp. VI, p. 49).

26,4 Possivelmente genuíno. Repete-se em Alex. Sev. 25,8; 28,6.

26,5-6 Cf. Aurélio Vitor, Caesares 24,6; Eutrópio, Breviarium VIII, 23; Festo Breviarium XXII. A prefeitura de Paulo é fictícia; 
ele é atestado no consilium de Papiniano (Dig. XII, 1,40). A H.A. conhece as duas versões da nomeação de Ulpiano; a opinião errônea presumivelmente deriva de Aurélio Vitor. Eutrópio nada informa sobre a prefeitura de Ulpiano; ele e Festo recordam tho apenas como magister scrinil/scriniorum e nada dizem sobre Paulo. A pretensa prefeitura de Paulo na H.A. deve provir de má compreensão de Aurélio Vitor.

26,9 in matrem Mamaeam unice pius fuit. Cf. Aurélio Vitor, Caesares 24,5: quae nomine Mammaea erat, plus quam pius. Cf. Jerônimo (GCS XLVII, 215) e Eutrópio, Breviarium VIII, 23. Barnes considera esta passagem derivada da K.G.. O restante da sentença a partir de ita ut Romae é da própria autoria da H.A., segundo Barnes; uma fiç̧ão baseada na existência, na própria época da H.A., de construções que levaram o nome de Maméia (Cf. Amiano XXVIII, 4,19: $a$ Silvani lavacro vel Mammaeae).

28,1 Os três consulados ordinários de Severo Alexandre (222, 226, 229); o autor pode ter tomado conhecimento através dos fastos.

28,6 Cf. 26,4 .

44,7 Theatrum Marcelli reficere voluit. BMC, R. Emp. VI, p. 146 e segs. Segundo a interpretação de S. Angiolillo (54), nestas moedas figura o teatro de Marcelo.

49,3-4 Relato de Dexipo sobre a esposa de Severo Alexandre. A H.A. refere-se a ela como cuisdam Macriani filia. Sabemos que a esposa de Severo Alexandre era Gnaea Seia Herennia Sallustia Barbia Orbiana Augusta (BMC, R. Emp. VI, pp. 61-63; pp. 142-143; p. 211; I.L.S., 486). A informação da H.A. de que seu pai foi nomeado César pode ter crédito: o Feriale Duranum parece registrar o aniversário de um L. Seius Caesar socer Augusti (I, 11-12) e no século V, Polêmio Sílvio registra um tyrannus desta época, chamado Salústio (Chr. min. I, 521). Mas o nome Macriano, emendado para Macrino, não tem confirmação.

49,5 Relato de Dexipo sobre o parentesco de Severo Alexandre com Heliogábalo.

50,1 iniit Parthicam expeditionem. Moedas de 231 aludem diretamente à partida do imperador e de Maméia para o Oriente (Profectio augusti - B.M.C., R. Emp. VI, pp. 76-79).

(54) - ANGIOLILlO, S., Una moneta di Alessandro Severo e Hist. Aug., Vit. Alex. XLIV, 7. Atti della Accademia Nazionale dei Lincei. Classe di Scienze Morali, Storiche e Filologiche. Roma, 28 (3-4), 1973: 349-356. 
52,2 Herodiano VI, 1,$7 ; 9,8$.

55,1-2 Cf. Aurélio Vitor, Caesares 24,2: Eutrópio, Breviarium VIII, 23; Festo, Breviarium XXII; Jerônimo (GCS XLVII, 215). $O$ relato da campanha persa de Severo Alexandre e seu retorno vitorioso é em sua maior parte composição livre do autor. Mas há uma base factual genuína, a qual provém seguramente da K.G..

56,1 Moedas de 233 confirmam o triunfo do imperador (B.M.C., R. Emp. VI, pp. 82 e segs.; pp. 206 e segs.).

56,6 terras interamnas ... recepimus. Medalha de bronze datada de 233 (tr. p. XII) com figura da Vitória coroando o imperador; aos seus pés duas divindades fluviais, o Tigre e o Eufrates (B.M.C., R. Emp. VI, p. 83).

57,3 Herodiano VI, 6,3.

59,1-6 Cf. Aurélio Vitor, Caesares 24,2-4; Eutrópio, Breviarium VIII, 23. Para a expedição Germânica de Severo Alexandre, a H.A. possui informação autêntica. A diferença de opinião sobre o lugar de sua morte $(59,6)$ demonstra indubitavelmente o conhecimento de Aurélio Vitor pela H.A.. Mas esta evita o erro de A. Vitor, que faz Severo Alexandre deslocar-se diretamente da Pérsia para o Reno.

59,7-8 Provém de Herodiano VI, 8,2; 9,4-6.

60,1 A duração do reinado de Severo Alexandre - imperavit annis XIII diebus VIIII. Outras fontes também dão como 13 anos e 9 dias (Eutrópio, Breviarium VIII, 23; Cronógrafo de 354 (MGH, Auct. Ant. IX, 147). O dies imperii de Severo Alexandre era 13 de março de 222 (Feriale Duranum, I, 23 ss) e Maximino foi cooptado em vários colégios sacerdotais em 25 de março de 235 (CIL VI, 2001). A informação sobre os "nove dias" talvez deva ser interpretado como o dia em que a morte de Severo Alexandre tornou-se conhecida em Roma.

A duração da vida de Severo Alexandre - vixit annis XXVIII mensibus III diebus VII está errada e provavelmente foi inventada: ele nasceu a $1^{9}$ de outubro (CIL $\mathrm{I}^{2}$, p. 255 , p. 274) em 209 ou 210 (Herodiano, V, 3,3; 7,4). Foi assassinado em março de 235. O Epitome De Caes. 24,4, atribui-lhe vinte e cinco anos.

60,2 Maméia, cuja ascendência sobre o filho é reconhecida por todos, foi morta juntamente com Severo Alexandre. Cf. Herodiano, VI, 8,3; VI, 9,7. 
61,8 Herodiano, VI, 78 ; VII, 2,1-2.

63,3 Apoteose de Severo Alexandre - senatus eum in deos retulit. Evidentemente não ocorreu em 235, sob Maximino. Severo Alexandre é intitulado divus após 238: ILS $1315=\mathrm{CIL}$ VIII, 627 (Mactar); IGrR III, 1033 = OGIS, 640 (Palmira); CIL $\mathrm{I}^{2}$, p. 255 . Não há provas da existência de cenotáfio ou tumba.

63,5-6 Parte disto presumivelmente deriva de Dexipo.

As informações são apresentadas em grande desordem na Vita, mas é possível distinguir cinco partes:

1 - caps. 1-14: o período anterior à ascensão ao império. Contém data e lugar de nascimento, nomes, características gerais, família e ancestrais, educação e presságios.

2 - caps. 15-28: administração, reformas internas.

3 - caps. 29-44: vida cotidiana do imperador; mas também dados sobre administração e obras públicas.

4 - caps. 45-64: campanhas militares, morte, funerais; também notícias isoladas e política interna.

5 - caps. 65-69: alocução a Constantino.

A Vita Alexandri descreve o reinado de Severo Alexandre por cate gorias, com pouca preocupação pela narrativa cronológica. De modo geral, as categorias são as seguintes: dados pessoais (nascimento, genealogia e parentesco, aparência física, educação e cultura, casamento, defeitos de caráter, morte e homenagens póstumas), hábitos pessoais, nomina, cargos e instituições, topografia e monumentos romanos, profecias e oráculos, vestes e bens mobiliários, legiões e equipamentos, moedas, duração do governo e da vida.

Seguindo o modelo de Suetônio, o autor transcreve documentos: discursos e aclamações, pretensamente extraídos de atas e anais. Na verdade, foram compostos pelo biógrafo, seguindo o modelo de documentos autênticos.

A Vita recorre a formas padronizadas existentes na literatura para criar uma variada coleção de profecias, oráculos e horóscopos.

Documentos falsificados e profecias não são os únicos recursos em. pregados na composição da biografia. O autor dispõe de um repertório de anedotas, anacronismos, trocadilhos etc... que o auxiliam na redação.

A H.A. inventou nomes de personagens, os bogus names estudados por Syme. O autor extraiu das fontes de que dispunha, nomes próprios, 
que foram transpostos de uma época para outra segundo as necessidades. Suetônio registra Mummiam Achaicam neptem Catuli (Galba, 3,4) como mãe do imperador Sulpício Galba; em Alex. Sev. 20,3, a esposa de Severo Alexandre é chamada de Memmia, Sulpicii consularis viri filia, Catuli neptis. Os dez educadores de Severo Alexandre citados em Alex. Sev. 3,2-3, não são autênticos; tampouco o são os biógrafos ou os conselheiros imperiais, excetuando-se Paulo e Ulpiano. Duvidoso é o poeta Sereno Samônico. Nomes favoritos são repetidos para diferentes personagens, às vezes com pequenas variações (55).

Há anacronismos evidentes, como a criação de soldados limitanei por Severo Alexandre (Alex. Sev. 58,4-5), a cunhagem de sólidos (Alex. Sev. 39,8) e medidas contra empréstimos a juros por senadores (Alex. Sev. 26,3 ). Como Suetônio e os epitomadores, inclui uma frase com a clássica informação sobre a duração da vida e do reinado, em anos, meses e dias na parte final da biografia.

A fantasia do autor é pródiga na criação de episódios em forma de anedotas; eles têm um objetivo preciso: ilustrar o comportamento do príncipe em certas situações. Apresentam sempre um sentido moral: mostram a repugnância do imperador por ladrões, pela corrupção e tráfico de influência na corte, etc. .

A biografia de Severo Alexandre na História Augusta, embora inspirada nos moldes suetonianos, deles se afasta pela extrema idealização, ao definir o perfil do "bom príncipe". Nele se misturam traços do optimus princeps antoniniano adicionados a elementos novos. Em contraste com Heliogábalo, apresentado como o mau príncipe, Severo Alexandre é caracterizado pelas virtudes morais e pelo respeito ao Senado. A obra une esquemas retóricos, já largamente difundidos, a temas inspirados na realidade do redator, expressando opiniões correntes nos meios senatoriais de Roma. A Vita Alexandri não pretende oferecer o retrato verista do imperador, mas compõe, com estereótipos, o modelo do príncipe-ideal da aristocracia senatorial pagã de Roma.

(*) - Abreviaturas: AC - L'Antiquité Classique. BHAC - Bonner Historia-Augusta-Colloquium. BMC - CARSON, R. A. G., Coins of the Roman Empire in the British Museum. London, The Trustees of the British Museum, 1962. CIL - Carpus Inscriptionum Latinarum. GCS - Die griechischen christlichen Schriftsteller der ersten (drei) Jahrhunderte. ILS - DESSAU, H., Inscriptiones Latinae Selectae. IGrR - Inscriptiones Graecae ad res Romanas pertinentes. JRS - Journal of Roman Studies. MGM Auct. Ant. - Monumenta Germaniae Historica (Auctores Antiquissimi). OGIS - DITTENBERGER, H., Orientis Graeci Inscriptiones Selectae. P. Oxy - Papiro Oxirrinco. RFIC - Rivista di Filologia $\boldsymbol{e}$ di Istruzione Classica.

(55) - SYME, R., BHAC $1964 / 65$, p. 260 ss. 